\title{
Health literacy in the pharmacy setting: defining pharmacotherapy literacy
}

\author{
Sean R. KING, David J. McCAFFREY III, Alicia S. BOULDIN.
}

Received (first version): 3-Jun-2011

Accepted: 15-Oct-2011

\begin{abstract}
Objective: All currently available definitions of health literacy may be considered quite general. Given the complex nature of the patient-pharmacy encounter and the varying tasks required to properly and successfully consume or administer medication or to adhere to a pharmaceutical care regimen, these available definitions may describe inadequately a patient's health literacy for the purpose of pharmacotherapy and pharmacist intervention. Therefore, the objective of this research was to conceptualize the

Pharmacotherapy Literacy construct.

Methods: Licensed pharmacists $(n=2,368)$ were mailed a questionnaire providing them with the Healthy People 2010 definition of health literacy and asked, "Given this definition, how would you define Pharmacotherapy Literacy?" A total of 420 usable surveys were returned of which $176(42 \%)$ included responses to the open-ended question concerning pharmacotherapy literacy. Responses were reviewed independently and collectively by the authors. Common themes were identified, compared and discussed until consensus was reached. An initial definition was formulated and distributed to six doctoral-trained academicians and practicing pharmacists who were asked to offer their opinions of the definition as well as suggestions for its improvement. The definition was modified and subjected to further review from 15 additional doctoral-trained academicians and practicing pharmacists who provided feedback concerning its improvement.

Results: Based on the recommendations received from the academicians and pharmacists, the following, final definition was formulated by the authors: Pharmacotherapy Literacy - An individual's capacity to obtain, evaluate, calculate, and comprehend basic information about pharmacotherapy and pharmacy related services necessary to make appropriate medication-related decisions, regardless of the mode of content delivery (e.g. written, oral, visual images and symbols).
\end{abstract}

\footnotetext{
Sean R. KING. MS, PhD. Assistant Professor. Department of Pharmaceutical Sciences, Union University School of Pharmacy. Jackson, TN (United States). David J. McCAFFREY III. RPh, PhD. Professor. Department of Pharmacy Administration, University of Mississippi School of Pharmacy. University, MS (United States).

Alicia S. BOULDIN. RPh, PhD. Associate Professor. Department of Pharmacy Administration, University of Mississippi School of Pharmacy. University, MS (United States).
}

Conclusions: As the ever-changing pharmacy environment continues to advance and become more complex in nature, a definition of health literacy specific to the pharmacy setting-thereby providing a name and a focus - may improve medication consumption, medication safety, and the patient-pharmacist relationship.

Keywords: Health Literacy. Drug Therapy. Medication Errors. Consensus.

\section{ALFABETISMO EN SALUD EN EL ENTORNO DE LA FARMACIA: DEFINIENDO EL ALFABETISMO EN FARMACOTERAPIA}

\section{RESUMEN}

Objetivo: Todas las definiciones actualmente disponibles de alfabetismo en salud (literacia en salud) pueden considerarse bastante generales. Dada la naturaleza compleja del encuentro farmacéutico-paciente, y las diversas tareas necesarias para consumir o administrar medicamentos con éxito y para cumplir con los regímenes terapéuticos, estas definiciones disponibles pueden describir inadecuadamente la literacia en salud de un paciente con el propósito de la intervención farmacéutica en farmacoterapia. Por tanto, el objetivo de esta investigación fue conceptualizar el constructo del alfabetismo en farmacoterapia.

Métodos: Se envió por correo un cuestionario a farmacéuticos en ejercicio $(n=2,368)$ proporcionándoles la definición de alfabetismo en salud del Healthy People 2010 y se les preguntó "Dada esta definición, cómo definiría el alfabetismo en farmacoterapia? Se recibieron un total de 420 cuestionarios utilizables, de los que $176(42 \%)$ incluían respuestas a la pregunta abierta relativa al alfabetismo en farmacoterapia. Las respuestas fueron revisadas independiente y colectivamente por los autores. Se identificaron los temas comunes, y se compararon y discutieron hasta que se llegó a un consenso. Se formuló una definición inicial y se distribuyó a seis académicos doctorados que ejercen en farmacia a los que se les pidió que dieran sus opiniones sobre la definición e hiciesen sugerencias para su mejora. La definición fue modificada y sometida a nueva revisión de otros 15 académicos doctorados y ejercientes en farmacia que proporcionaron un retorno en relación a la mejora.

Resultados: Basados en las recomendaciones recibidas de los académicos y de los farmacéuticos, los autores formularon la siguiente definición final: Alfabetismo en farmacoterapia (literacia en 
farmacoterapia) - La capacidad individual de obtener, evaluar, calcular y comprender información básica sobre farmacoterapia y servicios relacionados con farmacia necesarios para tomar decisiones apropiadas relativas a medicamentos, independientemente del modo en que se recibe el contenido (p.e. escrito, oral, imágenes visuales, y símbolos).

Conclusiones: Como el entorno siempre cambiante de la farmacia continúa a avanzar y hacerse más complejo, una definición de alfabetismo en salud específica para el medio farmacéutico- por tanto, que proporcione un nombre y un foco - puede mejorar el consumo de medicación, la seguridad de los medicamentos y la relación pacientefarmacéutico.

Palabras clave: Alfabetización en Salud. Drug Therapy. Errores de Medicación. Consenso.

\section{INTRODUCTION}

Literacy as defined by the American Heritage Dictionary is "the ability to read and write". The National Center for Education Statistics (NCES) expands this definition and conceptualizes functional literacy as "using printed and written information to function in society, to achieve one's goals, and to develop one's knowledge and potential". ${ }^{2}$ Literacy is further divided into three distinct levels by the NCES: 1) prose literacy or "the knowledge and skills needed to perform prose tasks, such as to search, comprehend, and use information from continuous texts," 2) document literacy or "the knowledge and skills needed to perform document tasks, such as to search, comprehend, and use information from noncontinuous texts in various formats," and 3) quantitative literacy or "the knowledge and skills necessary to perform quantitative tasks, such as to identify and perform computations, either alone or sequentially, using numbers embedded in printed materials".

The functionally illiterate are distinguished from the illiterate in that they can read and write in their native language (e.g., English); however, they do so with varying degrees of speed, style, and grammatical correctness. Functionally illiterate individuals share the inability of performing fundamental tasks such as following written instructions. As a result, like illiterate persons, functionally illiterate persons cannot function effectively in society when relying solely on written materials. As such, native English speakers may be either functionally illiterate or illiterate. Non-English speakers would typically be defined as illiterate in our largely English dominant health care system.

The term "health literacy" was first mentioned in the literature by Simonds (1974) in a call for schoolbased health education that would permit students to become just as educated in health as they are in traditional subjects such as math and history. ${ }^{3}$ Since that time, several definitions have been offered attempting to conceptualize fully this construct. (e.g. 4-7) Table 1 provides a description of these commonly used definitions. These definitions vary in the degree to which they attempt to explain health literacy and describe various skills required to be "health literate". Research applying these definitions has shown those possessing limited health literacy skills have less knowledge of chronic disease and self-management skills ${ }^{8,9}$, higher health care $\operatorname{costs}^{10}$, an inappropriate understanding of written health care information ${ }^{11}$, worse health status and less understanding about their medical conditions and treatment ${ }^{12}$, use preventive health services less frequently, and engage in riskier health behaviors. ${ }^{13}$ For the purposes of this research, health literacy was operationalized according to the definition offered by Healthy People 2010 as "the degree to which individuals have the capacity to obtain, process, and understand basic health information and services needed to make appropriate health decisions".

One of the innate challenges associated with poor health literacy is the identification of affected individuals. The limited literacy skills of patients often goes undetected by health care professionals partly because the problem is so widespread and can affect anyone. While education is important, it is known that education level alone is not shown to determine appropriately an individual's health literacy skill. ${ }^{14}$ Studies have found that the largest group in the U.S. population with below average literacy scores was comprised of American born, Caucasian, English speakers. Others with below average literacy scores included the poor, members of ethnic and cultural minorities, those living in southern and western areas of the United States, individuals with less than a high school diploma or GED, persons older than 65 years, those having physical or mental disabilities, prisoners, the homeless, and military recruits. ${ }^{2}$ Across all groups, shame and stigma are associated with limited literacy skills, so much so that spouses and children

\begin{tabular}{|c|c|l|}
\hline \multicolumn{3}{|c|}{ Table 1. Commonly used definitions of Health Literacy } \\
\hline Authors & Year & \multicolumn{1}{c|}{ Definition } \\
\hline $\begin{array}{c}\text { Parker, Baker, Williams, } \\
\text { and Nurss, p. } 537^{7}\end{array}$ & 1995 & $\begin{array}{l}\text { being able to apply literacy skills to health-related materials such as prescriptions, } \\
\text { appointment cards, medicine labels, and directions for health care }\end{array}$ \\
\hline $\begin{array}{c}\text { World Health } \\
\text { Organization (WHO) } \\
\text { Nutbeam, p.357 }\end{array}$ & 1998 & $\begin{array}{l}\text { health literacy represents the cognitive and social skills which determine the } \\
\text { motivation and ability of individuals to gain access to, understand, and use } \\
\text { information in ways which promote and maintain good health }\end{array}$ \\
\hline $\begin{array}{c}\text { American Medical } \\
\text { Association Ad Hoc } \\
\begin{array}{c}\text { Committee on Health } \\
\text { Literacy, p. 553 }\end{array}\end{array}$ & 1999 & $\begin{array}{l}\text { a constellation of skills, including the ability to perform basic reading and numerical } \\
\text { tasks required to function in the health care environment. Patients with adequate } \\
\text { health literacy can read, understand, and act on health care information }\end{array}$ \\
\hline $\begin{array}{c}\text { Healthy People 2010 } \\
\text { Ratzan and Parker, p.v }\end{array}$ & 2000 & $\begin{array}{l}\text { the degree to which individuals have the capacity to obtain, process, and } \\
\text { understand basic health information and services needed to make appropriate } \\
\text { health decisions }\end{array}$ \\
\hline
\end{tabular}


may be unaware of the issue. ${ }^{4}$ Because many patients do not admit readily or at all to possessing inadequate literacy levels and given affected individuals cannot be discerned visually, low literacy is described as a "quiet disability". ${ }^{15}$

Health literacy was first assessed specifically in the United States during the 2003 National Assessment of Adult Literacy (NAAL). It was discovered that while the average quantitative literacy scores of adults increased eight points, the average prose literacy and document literacy did not differ significantly. The NAAL revealed that $14 \%$ of American adults possessed "below basic" health literacy skills with an additional $22 \%$ possessing only "basic" health literacy skills. The percentages of individuals possessing "below basic" and "basic" health literacy skill were found to increase with age. $^{16}$ Therefore, a significant number of American adults may not possess the skills necessary to function adequately in a health care environment. This is especially true as it relates to the elderly population who in general are prescribed more medications.

A factor that has yet to be considered adequately is the effect that inadequate levels of functional health literacy have on a patient's experience with pharmacy and pharmaceuticals. Available definitions of health literacy are general in scope and do not differentiate between health care environments. The objective of this research was to describe an initial attempt to conceptualize Pharmacotherapy Literacy. In doing so, this paper promotes attention to the literacy needs of patients, specifically within a pharmacy setting.

\section{Prevalence of Inadequate Functional Literacy and its Applicability to Pharmacy}

Some 40-44 million U.S. residents are functionally illiterate and an additional 50 million have only marginal literacy skills. ${ }^{2}$ These results indicate that approximately one-half of the U.S. adult population lacks adequate reading or computational skills to function fully in today's environment. ${ }^{4}$ This is especially true in terms of addressing new situations or navigating the complex nature of the U.S. health care system. ${ }^{13}$ From a pharmacist's perspective, the most important finding of the 1993 National Adult Literacy Survey (NALS) is that for more than 90 million Americans, it is difficult to comprehend vital health information such as dosage instructions on medication containers. ${ }^{16,17}$

Evidence exists in the literature supporting the link between poor health literacy, inappropriate medication use, and poor health outcomes. It is well documented that inappropriate medication use is associated with negative outcomes such as increased hospital stays and costs ${ }^{18}$ and emergency department visits and hospital admissions. ${ }^{19} \mathrm{~A}$ large number of such outcomes are preventable ${ }^{20,21}$ and are among the most preventable health related threats, particularly within the elderly population. ${ }^{21}$ The consequences of inadequate health literacy are many and varied, and many factors are shown to affect the health literacy skills of patients.
Individuals with inadequate health literacy skills have a wide range of communication difficulties, all of which have the potential to undermine health outcomes and quality of life at both an individual and community level. ${ }^{12,22,23}$ Inadequate functional health literacy also may result in significant additional costs to the health care system through suboptimal or inappropriate medication use ${ }^{24}$ resulting in significant consequences not only for individual health but for the entire health care system. This is especially true given that those with inadequate literacy skills are less likely to comprehend written or oral information, to adhere to medication regimens, keep appointment schedules, or successfully navigate the health care system. ${ }^{25}$ Evidence also exists indicating that patients with poor health literacy skills also have an increased risk for hospitalization ${ }^{26,27}$ and the extent to which they are capable of acting upon medication instructions may be compromised. 6,28

Further complicating matters for those with poor health literacy skills is the fact that the majority of health care-related materials are written at a tenth grade reading level or higher. ${ }^{29}$ This may pose a major problem given that the majority of adults read at an eighth or ninth grade level. Additionally, close to one-half of adults are not capable of understanding printed health care materials, between twenty-one and twenty-three percent read at a fifth grade level or lower, and almost ninety million have fair to poor literacy skills. ${ }^{2}$

\section{Pharmacists' Expectations of Patients}

The ability to comprehend written health information such as that found on medicine bottles is an important component of any health care experience. ${ }^{11}$ Therefore, poor functional literacy skills may keep patients from receiving ultimately the care they need. Health care professionals, including pharmacists, often take for granted their patients' ability to read prescription information, health forms, and other health related publications and to overestimate what they can comprehend. ${ }^{15}$ However, given that a large portion of patients read with only marginal literacy skill, it is often difficult for them to comprehend written health information such as that pertaining to dispensed medicine. For instance, pharmacists expect their patients to consume their medications and properly follow any medication therapy management plan. In order to meet these expectations, it is important that patients possess not only adequate information but also appropriate reading, computational, and selfmanagement skills to utilize that information. ${ }^{6,28}$

Pharmacists, like other health care providers, often use language typically not understood by their patients. ${ }^{14}$ Moreover, it is not uncommon for healthcare providers, including pharmacists to rely heavily on written patient education materials (e.g., patient information leaflets/printouts) as opposed to the use of extensive patient counseling (i.e., verbal). As a result, patients may fail to acquire the knowledge and skill necessary to obtain additional follow-up information concerning their health care in the event that they experience treatment-limiting side effects. The patient's responsibility would 
involve taking appropriate actions on the basis of the instructions given by a pharmacist, such as monitoring medication effects (both beneficial and adverse effects), what to do in the case of a missed dose, and how, when, and if to obtain refills; a firm understanding of such instructions by the patient is critical. Unfortunately, differences often exist in what patients actually comprehend and what health care providers, including pharmacists, expect them to know or think they know. It has been demonstrated that patients with poor literacy skills significantly are less likely to understand and remember medication advice $^{6}$ and more likely to have trouble comprehending even what the majority of health care professionals would consider the most basic of medication instructions. ${ }^{28}$

Profession-driven impetuses should encourage action on the part of the individual providers. However, it may be the case that the individual does not always perceive the need. Literacy regarding one's pharmaceutical regimen sometimes fails where pharmacists may assume it would not. For example, common warning and auxiliary labels that are attached typically to medication vials may not be interpreted as a pharmacist would assume. These may have been tacitly assumed to be easily interpreted by those with both high and lower literacy. The results from Wolf et als (2006) study of the common causes of misunderstanding prescription drug warning labels among adults with low literacy skills suggests that patients lacking appropriate literacy skills were significantly more likely to misinterpret the eight most commonly used prescription drug labels than were those with higher literacy skills. It was also discovered that the most common causes of label misunderstanding included multi-step directions, text reading difficulty, use of icons (familiarity), use of color, and message clarity. ${ }^{30}$ So even those messages (on labels, in these cases) that were assumed to be understood may suffer from literacy limitations that are not obvious. Thus, there is need for an enhanced focus on health literacy particularly when it comes to its influence on pharmacotherapy and pharmacy practice. For pharmacists, this focus should ideally reflect specific areas of the patient medication taking experience that they can influence. Providing a definition of health literacy that spotlights those areas may enhance pharmacist participation in addressing health literacy matters.

Poor functional health literacy skills introduce the possibility of adverse consequences from pharmacy's perspective. Patients with limited health literacy skills are at an increased risk of consuming or administering inappropriate dosages, consuming medications at wrong times, and using incorrect routes of administration. For the aging population, the associated increase in medication consumption, along with the addition of new medications to the market increases the complexity of drug regimens as well as the possibility of drug interactions and adverse effects. The untoward effects of this issue are likely to be exacerbated by poor health literacy. Without appropriate pharmacist intervention, inadequate health literacy will continue to place patients at an increased health risk. ${ }^{14}$

\section{The Need for a Pharmacy-Specific Definition of Health Literacy}

In 2002, the American Society of Health System Pharmacists (ASHP) officially adopted a policy concerning health literacy which calls on pharmacists to actively seek opportunities to support research on health literacy as it relates to patient-pharmacy encounters. ${ }^{31}$ The policy calls for pharmacists to consider both the patient's general and health literacy skills when communicating medication information to patients. ASHP also called for educational programs, which would better prepare pharmacy students, residents, and practitioners to assess the general and health literacy skills of patients. ${ }^{31}$

Additionally, the Medication Therapy Management (MTM) services section of the 2003 Medicare Modernization Act (MMA) suggests that the medication consumption process is unique and requires different abilities above and beyond actions undertaken in other health care contexts. MTM services are intended to optimize therapeutic outcomes for targeted beneficiaries through improvements in medication use and reductions in adverse drug events that may result from pharmacist intervention. According to the MMA, MTMS may serve as a means of assisting in the understanding and promotion of appropriate medication consumption and recognition of adverse drug events and inappropriate medication use

All currently available definitions of health literacy may be considered quite general. Due to the complex nature of the patient-pharmacy encounter and the varying tasks required to properly and successfully consume or administer medication, or to adhere to a pharmaceutical care regimen (e.g., reading, recalling, comprehending, numeracy related tasks), these available definitions may describe inadequately a patient's health literacy for the purpose of pharmacotherapy and pharmacist intervention. This provided the impetus for this research and the development of a definition of Pharmacotherapy Literacy.

\section{METHODS}

\section{Sample}

The sample for this study was obtained as part of the biennial Pharmacist Compensation Survey, which is a service provided by the Mississippi Pharmacists Association in cooperation with The University of Mississippi's Department of Pharmacy Administration to Mississippi pharmacists. The names and addresses of pharmacists were obtained from the State Board of Pharmacy. All pharmacists licensed in and residing in the State were mailed a questionnaire and cover letter explaining the purpose of the investigation and asking for their participation $(n=2,368)$. A reminder postcard was sent during the second week following the delivery of the surveys in an attempt to achieve a higher response rate. This study was approved by the University's Institutional Review Board (IRB). 
In addition to questions that assessed compensation and benefits of Mississippi pharmacists, the questionnaire included the Healthy People 2010 definition of health literacy, "the degree to which individuals have the capacity to obtain, process, and understand basic health information and services needed to make appropriate health decisions". 7

Immediately following this definition, the pharmacists were asked, "Given this definition how would you define Pharmacotherapy Literacy?"

\section{RESULTS}

Following the six-week data collection period, 427 surveys were received, seven of which were incomplete and not included in subsequent analyses. A description of the sample is provided in Table 2. Of the 420 usable surveys 176 (42\%) included responses to the open-ended question concerning pharmacotherapy literacy. All responses were reviewed independently and collectively by the authors. Common themes were identified and then compared and discussed until consensus was reached. The most common theme identified was related to the comprehension of medication instructions. The word "understand" was cited within 130 of the 176 responses to the query. Other common themes identified pertained to medication side-effects, why the medication was prescribed, adherence to medication regimens, possible interactions and what to do in the instance of missed doses.

\begin{tabular}{|lr|r|}
\hline \multicolumn{2}{|l|}{ Table 2: Sample Description } & \\
\hline Practice Setting & Institutional & $34.0 \%$ \\
& Independent & $30.9 \%$ \\
& Chain & $35.1 \%$ \\
\hline Managerial Status & Owners & $11.2 \%$ \\
& Manager & $31.0 \%$ \\
& Staff & $57.8 \%$ \\
\hline Gender & Male & $50.8 \%$ \\
& Female & $49.2 \%$ \\
\hline
\end{tabular}

To be consistent with the three levels of literacy described by the NCES (i.e., prose, document and quantitative $)^{2}$, the authors formulated an initial definition from the survey responses and distributed it to a group of six doctoral-trained academicians and practicing pharmacists. These individuals were asked to offer their opinions of the definition as well as suggestions for its improvement. Based on these recommendations the following, definition was formulated by the authors:

Pharmacotherapy Literacy - An individual's capacity to obtain, evaluate, calculate, and comprehend basic information about pharmacotherapy and pharmacy related services necessary to make appropriate medication-related decisions, regardless of the mode of content delivery (e.g. written, oral, visual images and symbols).

Feedback concerning this version of the definition was then sought from a panel of 15 additional doctoral-trained academicians and practicing pharmacists. Suggestions offered from these individuals included changing "capacity" to "ability." It was the consensus of these individuals that the word "ability" better emphasized the physical and cognitive efforts individuals must demonstrate in order to follow a pharmaceutical regimen adequately. It was also suggested that "basic information" be modified to further elucidate that the information in question refers to the care of a specific patient and not patients in general. Therefore, "basic information" was changed to "patient-specific information." Finally, it was suggested that verbiage be added to the definition reflecting the patient's ability to correctly consume or administer their medications on a daily basis. The reviewers did not believe the manner in which the definition was worded currently necessarily reflected their abilities to properly act upon instructions or to care for themselves. Comments and suggestions from these individuals lead to the development of the following, final definition:

Pharmacotherapy Literacy - An individual's ability to obtain, evaluate, calculate, comprehend and properly act upon patientspecific information concerning pharmacotherapy and pharmaceutical services necessary to make appropriate medicationrelated decisions, regardless of the mode of content delivery (e.g. written, oral, visual images and symbols).

\section{DISCUSSION}

Based on the responses from those pharmacists who participated in the study there appeared to be support for the development of the Pharmacotherapy Literacy definition and the belief that it was a distinct, but related, construct from health literacy. This is one of the first attempts made at breaking the health literacy construct down into its component parts, and to our knowledge the first attempt at conceptualizing Pharmacotherapy Literacy. The definition of Pharmacotherapy Literacy presented here takes into account the importance of an individual's abilities to obtain basic information concerning pharmacotherapy (e.g., medication directives), cognitively process the information whether it is through written, oral, or other visual means, evaluate the information for relevance and reliability, judge the information in terms of its importance to personal health and well-being, and comprehend the importance of this information as it relates to their health, as well as how to adhere properly to a medication regimen (e.g., appropriate medication consumption).

One important distinguishing feature of the Pharmacotherapy Literacy definition from that of health literacy offered by Healthy People $2010^{7}$ is the recognition that medication-related information is communicated in a variety of formats (i.e., regardless of the mode of delivery). Medication information, particularly prescription medication information, is often provided to patients through multiple modes of delivery (e.g., written, oral, visual). While some patients are capable of 
understanding and processing all modes of communication, many may rely more heavily on a single mode, such as oral instructions. It is believed this may be especially true concerning patients with classically-defined inadequate health literacy skills.

Although much emphasis concerning health literacy has been centered on written words and numbers, comments provided by pharmacist respondents suggested that some patients may experience difficulties understanding the spoken word due to hearing impairment, limited English proficiency, or a lack of understanding of pharmacy jargon which along with text-based patient-information leaflets is an often used mechanism by which regimen information is shared directly with the patient by the pharmacist. For example, some of the pharmacy respondents stated:

"Such information is too complicated for most elders to understand."

"Pharmacists need to find out what level to speak on or how to make patients understand what you are saying and not say too much so patients will remember."

"Most patients do not understand the basic language of a medication's instructions for use and dosage. Therefore it is important to make sure you make the information as easy to understand as possible."

It was also noted by pharmacists responding to the survey that images or visual symbols (e.g., lacking verbal or numeric content) may be misinterpreted. Any or all of these modes of message transmission may fail someone with poor numeracy skills, as many aspects of pharmacotherapy involve the patient's ability to understand and apply numeric information. As indicated by respondents of the survey, examples include those images intended to communicate:

"an understanding about proper medication storage, administration, and dosing, including amount and frequency..."

"the drug's use and how to take each including with/without food, time of day, or until all gone etc."

This is concerning given the possibility that patients who are unable to recall what was said during the counseling session may call and ask their pharmacist or may rely solely on the pictures contained on the prescription warning labels. This may be especially true concerning those with hearing impairments that rely more on written instructions and those with limited English proficiency who rely more on auxiliary labels.

Reading, recalling and comprehending written, pharmacy-related information are important elements of a pharmacotherapy regimen and were taken into consideration when drafting the definition of Pharmacotherapy Literacy. However, it is also believed by placing more emphasis on an individual's ability to "calculate", the Pharmacotherapy Literacy definition will prove useful in focusing the attention of practitioners and researchers to the difficulties patients sometimes have with the many numeracy-related tasks involved with consuming medications (e.g., stepped tablet regimens, calculating/measuring liquid dosages, or drawing insulin into a syringe for injection). It may also help focus practitioner attention on medication-related instructions provided to patients using symbols or through counseling sessions (spoken) with pharmacists. The importance of numeracy skills is made evident by the inclusion of its assessment in the 2003 NAAL, the TOFHLA and the Newest Vital Sign (NVS). Given the high prevalence of numeracy-related tasks involved with the medication taking experience, it is inappropriate to assume that patients; especially those with inadequate health literacy, can comprehend adequately the complexity of the behaviors they are expected to perform.

The assessment of the health literacy skills of individuals, its consequences, and the burdens it places on society as well as the health care system is a relatively new area of inquiry; however, it is growing in interest among the research community and from practitioners alike. ${ }^{32}$ Current definitions of health literacy may be considered too general in scope and do not adequately encompass all aspects of every health care environment, the pharmacy environment in particular. This position is supported partially by the recent introduction of the oral health literacy ${ }^{33}$ and mental health literacy ${ }^{34}$ constructs. Fearing the possibility that many people may be unable to locate services and adequately comprehend information concerning oral health, Healthy People 2010 set objectives specifically relating to oral health. In doing so, they defined and used the term "oral health literacy". ${ }^{33}$ Additionally, Jorm (1997) introduced the term "mental health literacy" and defined it as "knowledge and beliefs about mental disorders which aid their recognition, management or prevention". ${ }^{34}$

While the development of discipline-specific definitions of health literacy may appear too cumbersome to some, it is believed such definitions will serve great benefit to those in each field. For instance, discipline-specific definitions of health literacy will allow practitioners and researchers to narrow their focus on issues associated with poor literacy skills that differ for each discipline or health care setting, allowing them to better serve the needs of their patients. Furthermore, given the requirements and the specific tasks involved with appropriately and successfully consuming medications and adhering to pharmacotherapy plans, it is inappropriate to group all health care environments under a single umbrella definition of health literacy.

The recent development of a pharmacy health literacy assessment tool by Jacobson and colleagues (2007) adds a critical piece of evidence in support of the development of a definition of health literacy specific to the pharmacy environment. ${ }^{35}$ This current research is but a first attempt to define Pharmacotherapy Literacy. It is expected that this definition will be debated among peers, both researchers and practitioners. However, 
this definition provides researchers with a foundation upon which to build empirical questions concerning much needed improvements in the areas of appropriate medication consumption and medication safety.

There exist limitations associated with this attempt at conceptualizing pharmacotherapy literacy. For example, only pharmacists in one state were asked to respond to the survey. Although doctoral-trained academicians and practicing pharmacists in two additional states assisted in the review and development of the definition, others may have different opinions about how Pharmacotherapy Literacy should be defined. Additionally, the definition of Pharmacotherapy Literacy presented may not reflect the opinions of those surveyed given the low response rate. Although an effort was made to achieve as large a response rate as possible through the use of reminder post cards, a larger sample size, especially concerning the response rate of the open ended Pharmacotherapy Literacy question, may have yielded information that would have altered the final definition. The possibility exists that a larger response rate could have been achieved through the use of methods such as the mailing of additional postcard reminders. Finally, the method used to conceptualize Pharmacotherapy Literacy appears to be unique. Obtaining the views and opinions of those practicing and researching in the field of pharmacy seemed to be the most logical method of conceptualizing this construct for its initial drafting. However, no attempt was made to return to pharmacist respondents for their reaction to what was created from their responses. The three levels of literacy offered by the NCES ${ }^{2}$ (i.e., prose, document and quantitative) served as the framework when drafting the final definition of Pharmacotherapy Literacy. Pharmacists were surveyed for their opinions in an effort to garner and demonstrate the profession's support of the concept. It was also believed that from a practical standpoint, surveying pharmacists may reveal aspects of the daily practice of community pharmacy that would have otherwise been omitted if considering only prose, document and quantitative literacy. Although, a potentially more effective methodology may have been to first craft the definition with consensus of the practicing pharmacists and researchers and then, survey community pharmacists. This may have afforded a better understanding of the opinions of the practicing community. However, the responses offered by the pharmacists did play an integral part in the development of the definition and seemed to correspond well with the three levels of literacy. The work presented here should be considered as pilot. It is strongly believed this definition of Pharmacotherapy Literacy should be subjected to a wider audience of practitioners and academicians alike for further research.

\section{CONCLUSIONS}

As the ever-changing pharmacy environment continues to advance and become more complex in nature, a definition of health literacy specific to the pharmacy setting - thereby providing a name and a focus-may improve medication consumption, medication safety, and the patient-pharmacist relationship. Given the positive response by those who responded to the survey of the idea that Pharmacotherapy Literacy is a separate and distinct construct, further inquiry into this matter in larger groups of practicing pharmacists and academicians is warranted. This research brings to the forefront the literacy needs of patients as they relate to the pharmacy setting.

\section{ACKNOWLEDGEMENTS}

The authors would like to acknowledge all the academicians and practitioners who participated in each phase of the project and thank you to the anonymous reviewers whose thoughtful comments improved the quality of the manuscript.

\section{CONFLICT OF INTEREST}

The authors have no conflicts of interest to disclose. This research did not receive funding support.

\section{References}

1. American Heritage Dictionary. Third Edition. New York, NY: Bantam Doubleday Dell Publishing Group, Inc. 1994.

2. Kirsch I, Jungeblunt A, Jenkins L, Koldtad A. Adult literacy in America: a first look at the findings of the national adult literacy survey. Washington, DC: National Center for Education Statistics, U.S. Department of Education. 1993.

3. Simonds SK. Health education as a social policy. Health Education Monograph. 1974; 2: 1-25.

4. Ad Hoc Committee on Health Literacy for the American Council on Scientific Affairs, American Medical Association. Health literacy: report of the council on scientific affairs. JAMA. 1999;281(6):552-557.

5. Nutbeam D. Health promotion glossary. Health Promot. 1986;1(1):113-127.

6. Ratzan SC and Parker RM. Introduction In: Selden CR, Zorn, M, Ratzan SC, Parker, RM, eds. National Library of Medicine Current Bibliographies in Medicine: Health Literacy. Vol. NML, Pub. No CBM 2000-1. 2000. Bethesda, MD. National Institutes of Health, U.S. Department of Health and Human Services. Available at: http://www.nlm.nih.gov/archives//20061214/pubs/cbm/hliteracy.pdf (Accessed April 2, 2007).

7. Parker RM, Baker DW, Williams MV, Nurss JR. The test of functional health literacy in adults: a new instrument for measuring patient's literacy skills. J Gen Intern Med. 1995;10(10):537-541.

8. Williams MV, Baker DW, Parker RM, Nurss JR. Relationship of functional health literacy to patients' knowledge of their chronic disease: a study of patients with hypertension or diabetes. Arch Intern Med. 1998;158(2):166-172.

9. Williams MV, Baker DW, Honig EG, Lee TM, Nowlan A. Inadequate literacy is a barrier to asthma knowledge and selfcare. Chest. 1998;114(4):1008-1015. 
10. National Academy on an Aging Society/Center for Health Care Strategies Low health literacy skills increase health care expenditures by $\$ 73$ billion. Center for Health Care Strategies Fact Sheet, Washington, DC. 1998.

11. Benson JG Forman WB. Comprehension of written health care information in an affluent geriatric retirement community: use of the test of functional health literacy. Gerontology. 2002;48(2):93-97.

12. Williams MV, Davis T, Parker RM, Weiss BD. The role of health literacy in Patient-physician communication. Fam Med. 2002;34(5):383-389.

13. Mika VS, Kelly PJ, Price MA, Franquiz M, Villarreal R. The ABCs of health literacy. Fam Community Health. 2005;28(4):351-357.

14. Hardin LR. Counseling patients with low health literacy. Am J Health Syst Pharm. 2005;62(4):364-365.

15. Baker DW, Parker RM, Williams MV, Pitkin K, Parikh NS, Coates W Imara M. The health care experience of patients with low literacy. Arch Fam Med. 1996;5(6):329-334.

16. Kutner M, Greenberg E, JinY, Paulsen C. The Health Literacy of America's Adults: Results From the 2003 National Assessment of Adult Literacy (NCES 2006-483). U.S. Department of Education. Washington, DC: National Center for Education Statistics, 2006

17. Nichols-English G. Improving health literacy: a key to better patient outcomes. J Am Pharm Assoc. 2000;40(6):835-836

18. Classen DC, Pestotnik SL, Evans RS, Lloyd JF, Burke JP. Adverse drug events in hospitalized patients: excess length of stay, extra costs, and attributable mortality. JAMA. 1997;277(4):301-306.

19. Schneitman-McIntire O, Farnen TA, Gordon N, Chan J, Toy WA. Medication misadventures resulting in emergency department patients at an HMO Medical Center. Am J Health Syst Pharm. 1996;53(12):1416-1422.

20. Dennehy CE, Kishi DT Louie C. Drug-related illness in emergency department patients. Am J Health Syst Pharm. 1996;53(12):1422-1426

21. Schneider PJ, Gift MG, Lee YP, Rothermich EA, Sill BE. Cost of medication-related problems at a university hospital. Am J Health Syst Pharm. 1995;52(21):2415-2418.

22. Foulk D, Carrol P, Wood SN. Addressing health literacy: a description of the intersection of functional literacy and health care. American Journal of Health Studies. 2001;17(1):7-14.

23. Kim SP, Knight SJ, Tomori C, Colella KM, Schoor RA, Shih L, Kuzel TM, Nadler RB, Bennett CL. Health literacy and shared decision making for prostate cancer patients with low socioeconomic status. Cancer Invest. 2001;19(7):684-691.

24. National Academy on an Aging Society/Center for Health Care Strategies (1998). Low health literacy skills increase health care expenditures by $\$ 73$ billion. Center for Health Care Strategies Fact Sheet, Washington, DC. Available at: http://www.agingsociety.org/agingsociety/publications/fact/fact low.html (Accessed February 2, 2011).

25. Schloman BF. Health literacy: a key ingredient for managing personal health. Online J Issues Nurs. 2004;9(2):6.

26. Baker DW, Parker RM, Williams MV, Clark WS. Health literacy and the risk of hospital admission. J Gen Intern Med. 1998;13(12):791-8.

27. Baker DW, Gazmararian JA, Williams MV, Scott, T, Parker RM, Green D, Ren J, Peel J. Functional health literacy and the risk of hospital admission among medicare managed care enrollees. Am J Public Health. 2002;92(8):1278-1283.

28. Youmans SL, Schillinger D. Functional health literacy and medicine use: the pharmacist's role. Ann Pharmacother. 2003;37(11):1726-1729.

29. Safeer RS, Keenan J. Health literacy: the gap between physicians and patients. Am Fam Physician. 2005;72(3):463468.

30. Wolf MS, Davis TC, Tilson HH, Bass PF, Parker RM. Misunderstanding of prescription drug warning labels among patients with low literacy. Am J Health Syst Pharm. 2006;63(11):1048-1055.

31. Young D. Low health literacy is high among Americans, studies say. Am J Health Syst Pharm. 2004;61(10):986-987.

32. Wallace L. Patient's health literacy skills: the missing demographic variable in primary care research. Annals of Family Medicine. Ann Fam Med. 2006;4(1):85-86.

33. U.S. Department of Health and Human Services, Office of Disease Prevention and Health Promotion. Healthy People 2010. Available at: http://www.healthypeople.gov/document/HTML/Volume2/21Oral.htm (Accessed: February 12, 2008).

34. Jorm AF, Korten AE, Jacomb PA, Christensen H, Rodgers B, Pollitt P. Mental health literacy: a survey of the public's ability to recognize mental disorders and their beliefs about the effectiveness of treatment. Med J Aust. 1997;166(4):182-186.

35. Jacobson KL, Gazmararian JA, Kripalani S, McMorris KJ, Blake SC, Brach C. Is Our Pharmacy Meeting Patients' Needs? A Pharmacy Health Literacy Assessment Tool User's Guide. (Prepared under contract No. 290-00-0011 T07.) AHRQ Publication No. 07-0051. Rockville, MD: Agency for Healthcare Research and Quality. October 2007. 